\title{
A MUNDANEIDADE DO CORPO: (RE)PENSAR A CULTURA INDIVIDUALISTA E SUAS IMPLICAÇÕES PARA A GESTALT-TERAPIA
}

\author{
The mundaneity of the body: (re)thinking the individualistic culture and its implications for \\ Gestalt-therapy
}
La mundanalidad del cuerpo: (re) pensar la cultura individualista y sus implicaciones para la Gestalt-terapia

Resumo: Consolidadas na modernidade, com a emergência do individualismo, as dicotomias mente $\mathrm{x}$ corpo, pessoa $\mathrm{x}$ mundo, organismo x ambiente, indivíduo x cultura fazem parte de um mesmo processo que, como aponta o antropólogo Le Breton, anatomizou o homem, o separou de seu meio e dos outros e objetificou a natureza. Tanto a Gestalt-terapia quanto o filósofo Merleau-Ponty propõem uma compreensão do ser humano que busca superar essas dicotomias. Para Merleau-Ponty somos encarnação em um mundo, tecidos com ele, logo, está afirmada a mundaneidade do corpo. Para a Gestalt-terapia, tanto o corpo como a noção de campo organismo/ambiente apontam também para essa compreensão não-individualista do homem. O objetivo deste trabalho é partir dessas referências interdisciplinares, para reafirmar a condição não individualista da existência e aprofundar essa perspectiva na teoria da Gestalt-terapia.

Palavras-chave: Corporeidade; Cultura; Individualismo; Merleau-Ponty; Gestalt-terapia

\begin{abstract}
Solidified in modernity, with the emergence of individualism, the dichotomies mind $\mathrm{x}$ body, person $\mathrm{x}$ world, organism $x$ environment, subject $x$ culture emerge from the same process that, as the anthropologist Le Breton points out, anatomized man, separated him from his environment and from others and objectified nature. Both Gestalt therapy and the philosopher Merleau-Ponty propose an understanding of the human being who seeks to overcome these dichotomies. For Merleau-Ponty we are incarnated in a world, woven with it, affirming the mundaneity of the body. For Gestalt therapy, both the body and the notion of organism/environment field also points to this non-individualistic understanding of human being. The objective of this work is, from these interdisciplinary references, to reaffirm the non-individualistic condition of existence and to deepen this perspective in Gestalt therapy theory.
\end{abstract}

Keywords: Body; Culture; Individualism; Merleau-Ponty; Gestalt Therapy

Resumen: Consolidadas en la modernidad, con la emergencia del individualismo, las dicotomías mente x cuerpo, persona x mundo, organismo x ambiente, individuo x cultura emergen de un mismo proceso que, como apunta el antropólogo Le Breton, anatomizó al hombre, lo separó de su medio y de los demás y objetivó la naturaleza. Tanto la Terapia Gestalt como el filósofo Merleau-Ponty proponen una comprensión del ser humano que busca superar esas dicotomías. Para Merleau-Ponty somos encarnación en un mundo, tejidos con él, luego, está afirmada la mundanidad del cuerpo. Para la Gestalt-terapia, tanto el cuerpo como la noción de campo organismo / ambiente apunta para esa comprensión no individualista del hombre. El objetivo de este trabajo es, pues, partir de esas referencias interdisciplinares, para reafirmar la condición no individualista de la existencia y profundizar esa perspectiva en la teoría de la Terapia Gestalt.

Palabras clave: Corporeidad; Cultura; Individualismo; Merleau-Ponty; Terapia Gestalt.

\section{Introdução}

Entre os fundadores da Gestalt-terapia, Laura Perls é conhecida pelo distintivo trabalho focado no corpo, fruto da sua experiência com práticas corporais e de dança diversas. Na obra Living at the boundary, - uma coleção de textos da autora nunca publicados em nosso país, Laura faz uma afirmação bastante curiosa ao vincular corpo e existência a partir de um trocadilho na língua inglesa:

Actually the point is to be a body . . . when you are a body, when you experience yourself totally as a body, then you are somebody. ... And when you don't have that, you very easily experience yourself as a nobody. ${ }^{1}$ (Perls, 1992, s/p)

Ao afirmar isso, Laura Perls nos aponta uma perspectiva que dialoga muito com o que o filósofo Merleau-Ponty afirma: nossa existência é sempre corpo no mundo com o outro. É como corpo que experimentamos e nos movemos no mundo, que encontramos com aquilo que nos surpreende exige

$1 \quad$ Na verdade, o objetivo é ser um corpo (...) quando você é um corpo quando, quando você se experiência totalmente como um corpo (body), então você é alguém (somebody) (...) E quando você não tem essa experiência, você muito facilmente tem a experiência de ser ninguém (nobody). [livre tradução] 
de nós trabalho e é como corpo que percebemos os outros humanos, e podemos gesticular para eles, dialogar e nos relacionar com eles (Merleau-Ponty, 2011).

Como é perceptível na citação de Laura Perls, a Gestalt-terapia - em especial a apresentada no livro fundador da abordagem - apresenta uma perspectiva não dicotômica, que se contrapõe às divisões entre corpo, mente, natureza e sociedade. A partir da influência da teoria organísmica de Kurt Goldstein - que também aparece na obra de Merleau-Ponty -, Perls, Hefferline e Goodman (1997) irão compreender corpo e mente como um organismo, isto é, uma totalidade (gestalt) que é apenas elemento de um campo organismo/ambiente. Para eles, a Psicologia não deve manter seu foco apenas no que acontece com o organismo, como tradicionalmente faziam as ciências humanas, mas nos processos que ocorrem no campo organismo/ambiente.

Com a noção de campo organismo/ambiente, os autores estão afirmando a condição de imbricação entre corpo e mundo. Isto está bem claro quando afirmam que "não há qualquer função, de animal algum, que se complete sem objetos e ambiente, quer se pense em funções vegetativas como alimentação e sexualidade, quer em funções perceptivas, motoras, sentimento ou raciocínio" (Perls et al, 1997, p. 42). As dimensões do campo organismo/ambiente seriam uma dimensão física, uma dimensão animal e uma dimensão sócio-cultural (que é a simbolização, a criação e a partilha de sentidos e significados, elementos de uma cultura). Estas três compõem uma totalidade complexa (Alvim, 2018, p. 28) que não pode ser reduzida a apenas um desses aspectos. No processo de contato, a experiência é sempre a apreensão dos fenômenos como uma totalidade sintética dessas dimensões, "o corpo é um todo pele, músculos, coração, pulmões, sangue, forças instintivas, crenças, valores, representações inscritas na carne - que é minha e também do mundo" (Alvim, 2018, p. 29).

Quando um cliente chega à clínica, conta de suas queixas, inseguranças, dúvidas, expõe suas necessidades, fala de seu sofrimento, chora ou ri, usa de voz clara, escolhe contar sobre determinado assunto e evitar outro, enfim, se expressa e age com o terapeuta naquele determinado campo, estão presentes naquela configuração uma rede complexa de elementos, que devem ser considerados todos sem a pretensão que haja algum mais "natural" ou "simples" que outro. Perls, Hefferline e Goodman afirmam que:

(...) não se podem considerar fatores históricos e culturais modificando ou complicando condições de uma situação biofísica mais simples, mas como intrínsecos à maneira pela qual todo problema se nos apresenta. (Perls et al., 1997, p. 43)
Compreender o ser humano a partir da noção de campo organismo/ambiente nos convida a ressignificar os saberes que se pautam numa compreensão do sujeito como indivíduo fechado. Nesse aspecto, é possível vislumbrar um fértil diálogo entre a Gestalt-terapia e a fenomenologia de Merleau-Ponty. Ambas sugerem uma compreensão de um corpo que não apenas habita um mundo, mas faz de seu próprio corpo mundo, repleto de histórias, vivências, experiências, cultura. Olhando por esse aspecto, a afirmação de Laura Perls com a qual abrimos esse capítulo ganha outras nuances: ser alguém (some-body) é partilhar também de um (corpo) mundo comum, ultrapassando os limites do individual ${ }^{2}$ e criar a partir do que o mundo nos oferece, produzindo novos sentidos a partir disso que nos é dado no campo.

Por outro lado, parece que nós, gestalt-terapeutas, ainda não conseguimos compreender essa proposta completamente. Uma parte da responsabilidade disso envolve o próprio momento histórico no qual a abordagem nasce, a história e o percurso de seus fundadores. Essa é a hipótese que Jean-Marie Robine (2005) apresenta no artigo "A Gestalt-terapia terá a ousadia de desenvolver seu paradigma pós-moderno?". O autor discute a existência de uma compreensão dicotômica predominante na Psicologia - e também partilhada por parte da Gestalt-terapia - de que self seria $\underline{o}$ self, uma estrutura interna/ intrapsíquica, em interação com o ambiente ou com o outro e que poderia ser descrito segundo o diagrama a seguir:

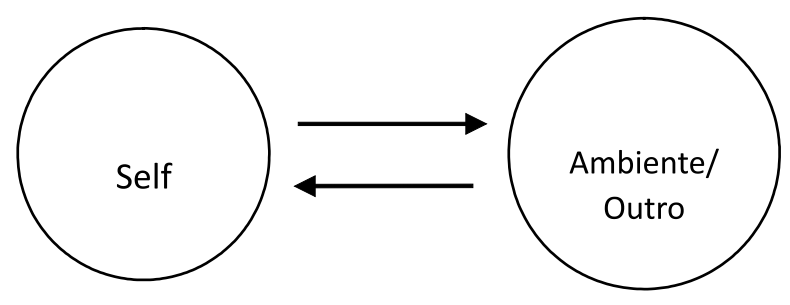

Figura 1. Diagrama self $\mathrm{x}$ ambiente

Na base do argumento de Robine (2005) está um postulado interessante: de que na teoria da Gestalt-terapia estão presentes concepções modernas e pós-modernas. Ele toma como exemplo dessa concepção moderna, o desenvolvimento dos trabalhos de Fritz Perls no período após a publicação do livro "Gestalt-terapia” (Perls et al., 1997). Robine critica a ênfase $\underline{\text { no autossuporte }}{ }^{3}$ presente no trabalho de Fritz e de 2 A discussão sobre a noção de indivíduo será abordada com detalhamento mais adiante neste trabalho, por enquanto basta a concepção presente no senso comum: um ser fechado em si, limitado pela sua pele e destacado do mundo, mesmo estando presente nele. 3 Aqui cabe acrescentar que essa crítica ao autossuporte não é hegemônica. Phillipson (2018), por exemplo, diz que "quando Perls escreveu sobre o "auto-suporte", isso não poderia consistentemente ser visto como negar a necessidade de conexão com o ambiente, porque o ambiente é inerentemente envolvido com o self" (Phillipson, 2018 , 368). De qualquer forma, consideramos que o mal entendido sobre essa dicotomia ainda persiste, não apenas na Gestalt-terapia, mas na Psicologia e ciências humanas em geral, e que a tese apresentada por Robine - que vai além da questão do autossuporte - é relevante. 
outros gestalt-terapeutas da época. O objetivo do trabalho terapêutico, nessa perspectiva, seria a saída do paciente da dependência do suporte ambiental para aquisição de autossuporte. O autor sublinha a oposição que Fritz faz entre self e ambiente, o que, segundo ele, seria contraditório com a noção de campo organismo/ambiente presente no livro Gestalt-terapia. Ele também aponta que um trabalho terapêutico baseado nessa premissa poderia gerar uma forma de egotismo, produzida pela própria terapia.

Diante desse panorama, consideramos o argumento de Robine (2005) e, neste trabalho, buscamos enfatizar a perspectiva de campo na teoria da Gestalt-terapia por considerá-la coerente com o desenvolvimento desse "paradigma pós-moderno" (op. cit) presente no livro originário da abordagem. A perspectiva de campo, como discutimos, é orientada por uma compreensão que busca superar as dicotomias do pensamento moderno. Como já apontamos, o filósofo Merleau-Ponty explora a corporeidade em seus diversos aspectos como uma via importante na sua tentativa de superar os prejuízos produzidos por essas dicotomias. De certa maneira, na teoria da Gestalt-terapia o corpo também tem lugar privilegiado, exatamente porque os fundadores - em especial, Fritz Perls, Paul Goodman e Laura Perls - vislumbravam a necessidade de uma abordagem integradora para compreender os gestos, a fala e o próprio lugar do terapeuta.

Uma das principais dificuldades para a compreensão e também o que fomenta a manutenção dos mal-entendidos em relação à perspectiva de campo é essa construção que pautou a subjetividade como algo fechado em si. Essa perspectiva individualista se tornou elemento para o solo de onde brota nossa experiência e a tomamos como algo dado. Mas será que foi sempre assim? O convite desse trabalho é estabelecer o contato com formas outras de compreender a relação eu x mundo, através da História, da Antropologia e da Filosofia. Acreditamos que o contato com essas outras perspectivas possa conferir outras tonalidades sobre a compreensão da própria teoria da Gestalt-terapia.

Dessa maneira, buscamos ser fiéis ao espírito gestáltico, marcado pela interdisciplinaridade e pela crítica aos especialismos e apostamos no diálogo com outras perspectivas. Como apontam as pistas citadas ao longo dessa introdução, o corpo se apresenta como caminho de superação das dicotomias clássicas, pois se apresenta como única maneira possível de estar no mundo e se relacionar com ele.

\section{Corpo e mundo, integração e divisão: elementos para uma compreensão.}

A tarefa de pensar e escrever sobre o corpo é sempre um desafio. De certa forma, poderíamos dizer que o corpo é um mistério, mas é um mistério na medida em que todos somos um mistério para nós mesmos, sempre inacabados, tendo sempre uma fa- ceta que escapa da nossa apreensão (Merleau-Ponty, 2004, 2011). Le Breton (2011) afirma que os saberes que possuímos do corpo são tributários de um estado social, de uma visão de mundo e de uma definição de pessoa, isto é, de uma determinada cultura. Em nossa experiência, apalpo meu braço e dou a resposta do senso comum em nossa cultura: o corpo que é carne, ossos, músculos, tecidos e fluidos, contido por esse revestimento, a pele. Essa compreensão é herança de uma série de saberes sobre o corpo - seria extenso numerar todos -, mas o individualismo moderno, segundo o autor, tem papel fundamental na instituição do que ele chama de "homem anatomizado".

No livro "Antropologia do Corpo e Modernidade" (Le Breton, 2011), este autor vai discorrer sobre a passagem de uma "antropologia cósmica” (Le Breton, 2011, p. 43) que vigorava na cultura popular medieval para o "homem anatomizado" (Le Breton, 2011, p. 86) . Segundo o autor, para essas culturas populares, o homem não se distinguia da tessitura do cosmos e da comunidade onde estava inserido e, nos festejos carnavalescos que invadiam as ruas, o “corpo grotesco” (Le Breton, 2011, p. 46) era a experiência dominante. Le Breton usa a denominação “corpo grotesco" para falar de um corpo que é "formado de relevos, de protuberâncias, ele transborda de vitalidade, está mesclado à multidão, indiscernível, aberto, em contato com o cosmo, insatisfeito com os limites que ele não cessa de transgredir" (Le Breton, 2011, p. 47).

Por outro lado, ele afirma que já era possível perceber também, principalmente entre as camadas eruditas, a elaboração um “corpo racional”, que é um protótipo do corpo moderno, um corpo "liso, moral, sem aspereza, limitado, reticente a toda transformação eventual. Um corpo isolado, separado dos outros, em posição de exterioridade com o mundo, fechado em si” (Le Breton, 2011, p. 48). Silva (1999) aponta que essa tendência é identificada através de "práticas de isolamento e preocupação por si, não comuns em períodos anteriores” (Silva, 1999, p. 8)

Assim, Le Breton (2011) afirma que há o desenvolvimento de um modo de compreender o mundo e o homem que se dissemina mais entre as camadas eruditas - as principais influenciadoras dos planos econômico e ideológico na transição para a modernidade -, mas que ainda não se espalhou para as camadas populares. Para estes, ainda não há uma concepção de indivíduo destacado do mundo que o cerca e os limites do corpo não correspondem aos limites da pessoa, antes,

O homem, indiscernível de seu enraizamento físico, é percebido em sua inclusão no seio das forças que regem o universo (...) As fronteiras da carne não demarcam os limites da mônada individual. Um tecido de correspondências mescla sob um destino comum os animais, as 
plantas, o homem e o mundo invisível. Tudo está ligado, tudo ressoa junto . . . não há qualquer ruptura significativa entre a carne do homem e a carne do mundo . . . . O corpo humano é, nas tradições populares, o vetor de uma inclusão, não o motivo de uma exclusão (no sentido de que o corpo vai definir o indivíduo e o separar dos outros, mas também do mundo); ele é o vinculador do homem a todas as energias visíveis e invisíveis que percorrem o mundo. $\mathrm{O}$ corpo não é mesmo um universo independente, fechado em si mesmo ... [mas] é um campo de força em poder de ação sobre o mundo, e sempre a ponto de ser influenciado por ele. (Le Breton, 2011, p. 49-50)

O corpo ainda não era concebido como um objeto possuído pelo sujeito, ele não pode ser considerado como algo separado do homem, mesmo na morte o corpo ainda é habitado de humanidade. Esse modo de compreender o corpo é perceptível nos relatos historiográficos que descrevem, por exemplo, a crença de que se fossem levados os restos mortais de uma vítima diante de seu assassino, elas sangrariam. De modo semelhante, se um homicida escapasse da polícia e fosse encontrado morto, seu cadáver seria desenterrado e lhe seria aplicado o castigo merecido. $\mathrm{O}$ corpo e a pessoa eram indiscerníveis. Isso também é perceptível nas obras de arte, onde o nobre ou aquele que tivesse condições financeiras para tanto, encomendaria uma pintura na qual seu rosto fosse estampado nas obras que representavam santos. Ter a imagem pintada ao lado dos santos, no céu, era também adquirir um estado de santidade.

Essa mesma concepção do corpo se revela no tabu em relação àqueles cujos trabalhos envolvem cortá-los, abri-los, sangrá-los, desmembrá-los. Os cirurgiões, barbeiros e açougueiros faziam parte de uma casta desprezada, mas necessária. Também eram vetadas as dissecções e todo o conhecimento anatômico vinha da comparação com outros animais, como o porco, que era considerado muito semelhante ao ser humano. Ao longo de todo seu argumento, Le Breton descreve uma compreensão de homem integrado existente naquele período: corpo, natureza, mundo e sociedade constituíam uma comunidade. Ao longo do tempo, essa compreensão integrada dará lugar a outro modo de ordenar o mundo que transformará esta relação com o corpo, a natureza e a sociedade: o individualismo.

Diversos autores (Dumont, 1993; Silva, 1999; Le Breton, 2011) vão descrever a emergência de um paradigma individualista ao longo do tempo. Dumont (1993) produz um abrangente trabalho, que remonta às tradições hindus, para discutir a produção de um protótipo de individualismo. Le Breton (2011) descreve alguns fatores envolvidos com essa transformação, que citamos aqui sem a pretensão de explorar profundamente esse processo. Segundo ele, fatores envolvendo a mudança do modelo de sociedade do feudalismo para o mercantilismo envolvem o surgimento de grandes centros urbanos, migração, busca da obtenção de sustento; o comércio e os bancos passam a ter grande importância na vida econômica e o comerciante se torna o "protótipo do indivíduo moderno" que, ao empreender e extrapolar os limites, faz de "seu interesse pessoal o móbile de suas ações, ainda que em detrimento do "bem geral"” (Le Breton, 2011, p. 60).

Le Breton também descreve um deslocamento da parte do corpo considerada órgão privilegiado; a mudança da boca, que era via de alimentação e comunicação com o mundo, para os olhos, que consomem a nova cultura erudita. Segundo o autor, a visão é o sentido-chave da Modernidade Renascentista. Com o desenvolvimento do retrato individual não-religioso na pintura, o rosto passa a ter lugar de importância, se tornando o lugar de individuação do homem, pois é a parte mais singularizada de nosso corpo. O corpo se torna o lugar de individuação do homem: "o indivíduo não é mais o membro [grifo do autor] inseparável da comunidade, do grande corpo social; ele se torna um corpo [grifo do autor] exclusivamente seu" (Le Breton, 2011, p. 66).

Desenvolve-se toda uma forma de individuação a partir do corpo: os retratos individuais tornam-se tendência nas artes, o rosto torna-se lugar de representação do homem, o corpo torna-se uma posse pessoal, desconectada do mundo, os artistas passam a assinar suas obras, fazendo-as suas, o enriquecimento pessoal se torna a forma de funcionamento da economia, a Reforma Protestante rompe com a estrutura religiosa e coloca o homem diante de Deus como uma questão pessoal. Desse modo, o corpo, com a dessacralização da natureza e a racionalidade científica, "não é mais o sinal da presença humana, indiscernível do homem: ele é sua forma acessória" (Le Breton, 2011, p. 71).

Concomitantemente, ele é desconectado da natureza pois precisa dominá-la, colocando-se no centro - o que caracteriza o humanismo renascentista antes ocupado pelo divino. O desenvolvimento dos métodos na filosofia e na ciência ocupam lugar central, possibilitando o controle e domínio da natureza.

A perspectiva da técnica, como Heiddeger (2007) coloca, nos ajuda a esclarecer a qualidade dessa mudança produzida e aprofundada pelas ciências modernas. O filósofo traz a noção de techné grega, apontando que seu significado original diz de um cuidado e uma entrega às próprias forças da natureza, maiores e mais poderosas que o homem:

(...) o campo que o camponês antigamente preparava, onde preparar ainda significava: cuidar e guardar. $\mathrm{O}$ fazer do camponês não desafia o solo do campo. Ao semear a semente, ele entrega a semeadura às forças do crescimento e protege seu desenvolvimento. (Heidegger, 2007, p. 381) 
Por outro lado, o techné na modernidade é marcado por um "desafiar", um exigir da natureza a matéria necessária à produção, sujeitando-a para explorá-la. O homem desafia o rio, ao "aprisioná-lo" e gerar mais pressão para a hidroelétrica, desafia a terra ao rasgá-la em busca de cada vez mais minério a cada vez menos tempo e o corpo também se torna mais um elemento para ser sujeitado e explorado.

Para isso, é necessário o "recuo" que o individualismo deu ao homem: distinguidos uns dos outros e do mundo ao redor a partir do seu corpo, que antes era lugar de vínculo e agora se mostra como fronteira, despe tudo de humanidade e o reduz ao lugar da matéria, objeto. É nesse sentido que Le Breton vai afirmar que a individuação do homem coincide com a dessacralização da natureza (Le Breton, 2011, p. 71)

Nesse sentido, Le Breton cita Descartes: "eu me considerei primeiramente como tendo um rosto, mãos, braços, e toda essa máquina composta de ossos e de carne, tal como ela aparece em um cadáver, a qual designei pelo nome corpo" (Le Breton, 2011, p. 95). A própria compreensão da existência proposta pelo filósofo passa por uma depreciação do corpo e uma reificação da Razão, do cogito: "penso, logo existo". O corpo, que antes era experienciado como elemento vivo do universo, agora pode ser visto como um "cadáver" ou até mesmo como uma máquina, sendo no pensamento moderno que surge a ideia do autômato.

Neste mundo da divisão, o corpo se torna fronteira entre um homem e outro. Perdendo seu enraizamento na comunidade dos homens, afastando-se do cosmo, o homem das camadas eruditas do Renascimento considera o fato de sua encarnação sob um ângulo contingente. Ele se descobre entulhado de um corpo. Forma ontologicamente vazia, senão depreciada, acidental, um obstáculo ao conhecimento do mundo . . . . O corpo é um resto . . . . A definição moderna do corpo implica que esse homem esteja separado do cosmo, separado dos outros, separado de si mesmo. O corpo é o resíduo desses três retiros. (Le Breton, 2011, p. 71)

A revolução industrial, central para o modelo capitalista, também provoca profundas transformações na sociedade, na cultura e nos modos de subjetivação. Gradativamente, o indivíduo se estabelece como o centro autônomo de onde partem as escolhas e valores, em detrimento das tradições ou da comunidade; vai-se consolidando um modo dualista que compreende o sujeito separado do seu corpo, levando à necessidade de questionar o lugar do corpo na vinculação social do indivíduo.

Mancebo \& Jacó-Vilela (2004) e Dumont (1993) propõem que o individualismo, como o conhecemos hoje, surge como uma produção sócio histórica que teve seu início na modernidade. Nesse ponto é importante diferenciar individualismo de indivíduo. Dumont faz essa diferenciação de forma bastante clara, discriminando o que ele denomina "indivíduo empírico" do "indivíduo moral" das sociedades individualistas:

1. O sujeito empírico [grifo do autor] da palavra, do pensamento, da vontade, amostra indivisível da espécie humana, tal como o observador encontra em todas as sociedades.

2. O ser moral [grifo do autor], independente, autônomo e, assim (essencialmente), não social, tal como se encontra, sobretudo, em nossa ideologia moderna do homem e da sociedade. (Dumont, 1993, p. 75)

Essa concepção do homem enquanto ser moral, independente e autônomo tornou-se um a priori para nossa cultura, transformando a maneira como experienciamos e percebemos a nós, ao nosso corpo e ao mundo.

Segundo Silva (1999), esse é um processo que decorrerá de um interesse pelo corpo que se concretiza na dominação e sujeição do mesmo. A depreciação do corpo frente à razão coincide com o processo de dessacralizar a natureza e retirar dela agência, colocando-a como objeto de passividade, de onde extraímos material e combustível para a produção. Esse movimento é reproduzido até os dias de hoje - ainda que com críticas cada vez mais acirradas contra ele. Sentimos seu impacto, por exemplo, nas tragédias naturais. Em novembro de 2015, uma barragem operada pela mineradora Samarco, estourou em Minas Gerais, "matando" o Rio Doce com a lama contaminada. Apesar de moderada mobilização pública, principalmente nas redes sociais, é notável o luto dos indígenas da Reserva Krenak que lamentaram e choraram a morte do Rio como quem chora a morte de um irmão ${ }^{4}$. O Rio Doce era vivo como eles.

Diante de tudo isso, ficamos com um quadro peculiar: por um lado, os avanços científico-tecnológicos. Por outro, temos como consequência a objetificação da natureza e do corpo, o avanço do tecnicismo, a dissociação do mundo circundante e uma série de fenômenos a isso relacionados: o individualismo intensificado, o ritmo da vida baseado nos ponteiros do relógio e não nos ciclos naturais, a ideia de que cada um de nós é um universo fechado, tendo início e fim em nós mesmos, abrindo outras questões. Diante dessas pistas, podemos concluir que há uma estreita ligação entre corpo e cultura e que as consequências do pensamento dicotômico tiveram reflexos importantes na história, na filosofia e nas ciências.

Destacamos o pensamento filosófico de Descar$4 \quad$ "'O rio já sabia que ia ser morto. Quando a sujeira veio, ele foi subindo chorando, fazendo barulho. E minha mãe chorando junto. Até hoje ela ainda não foi ver o rio', descreve Tatiana, que é filha da cacica Laurita Maria Félix Krenak, 80, a mais velha da tribo.” (Maia \& Sevilla, 2015) 
tes que institui uma separação entre mente e corpo, res cogitans e res extensa, e que é icônico no período da passagem da idade media para a Idade Moderna, é criticado por Le Breton e também por Merleau-Ponty. Ambos retomam esse pensamento e Merleau-Ponty (2011), em consonância com a elaboração que Le Breton (2011) faz ao dizer que o corpo se torna "resíduo", aponta que, enquanto "ego meditante" o sujeito da consciência está separado do mundo e das coisas, afastado do próprio corpo, que pode ser compreendido como uma "coisa entre as coisas, como uma soma de processos físico-químicos” (Merleau-Ponty, 2011, p. 9). Merleau-Ponty faz uma crítica à centralidade do "eu cogito" na determinação do sentido e da verdade, critica o "pensamento de sobrevôo”, isto é, um modo de observar desconectado do mundo que seria capaz de fazer escrutínio de todas as coisas, a partir da observação de fora, como se sobrevoasse o mundo (Merleau-Ponty, 1980).

O filósofo propõe a afirmação de uma subjetividade encarnada, que habita o mundo com as coisas e, desse lugar, pode falar sobre elas e por falar desse lugar de encarnação também reconhece as limitações de seu saber, compreendendo-o como uma perspectiva e uma síntese de outras perspectivas que pode apenas subsumir. Mas, ao mesmo tempo, um ser encarnado nas coisas pode senti-las e experimentá-las de uma forma muito menos estéril e asséptica, fazendo-o não apenas coisa no mundo, mas mundaneidade no corpo.

\section{Merleau-Ponty e o corpo encarnado no mundo}

Para Merleau-Ponty, o corpo é um "nó de significações vivas” e é o lugar da experiência. Com isso, ele se opõe a uma perspectiva que compreende a consciência racional como lugar da experiência e que, por conseguinte, pensa a percepção, a memória, o comportamento, a projeção de futuro a partir dessa consciência reflexiva. Merleau-Ponty irá afirmar que "A consciência reflexiva não é a forma canônica da consciência, nem sua única forma, nem a primeira. Depende da consciência perceptiva, indiscernível de um corpo cognoscente” (Merleau-Ponty, 2011).

Ao afirmar que a consciência reflexiva é indiscernível de um “corpo cognoscente”, o filósofo compreende o corpo como ser que apreende o mundo não de fora dele, como se o sobrevoasse, mas encarnado: "ser no mundo". Ser no mundo aponta para uma percepção pré-objetiva, onde corpo e mundo formam uma totalidade perceptivo-prática, um corpo engajado e agindo de modo intencional com a situação que se apresenta. Nossa percepção nunca abarca a significação total do mundo, mas oferece uma significação prática, um "reconhecimento corporal” articulado com a situação que se apresenta e que "pede os movimentos do animal assim como as primeiras notas da melodia pedem um certo modo de resolução sem que ele seja conhecido por si mes- mo” (Merleau-Ponty, 2011, p. 118).

Enquanto que para Descartes, a existência é pautada por um Cogito, um "eu penso", em Merleau-Ponty, ela é um “eu posso”. O corpo deixa de ser apenas um mecanismo de partes justapostas, ligadas umas às outras por articulações, músculos, nervos e terminações nervosas, e se torna uma espécie de caleidoscópio, que se espalha ou se recolhe intencionalmente no mundo, de acordo com certa ação com a qual se engaja. Para o filósofo, existe um mundo dado, que dança comigo, que me convida a dar certos passos em detrimento de outros. Esse mundo, para ele, possui duas dimensões: um mundo físico e um mundo inter-humano. Há a natureza e objetos dos mais variados: ferramentas construídas pela nossa cultura, como talheres, telefone, produtos de higiene pessoal e máquinas fabris. Também há o outro humano, uma linguagem comum, uma série de códigos de comunicação, partilha de gestos e conduta.

Quando organizamos a posição do nosso corpo - nossa postura, como falamos, agimos ou estendemos nossa mão para pegar um copo -ao invés de uma associação de dados de localização dos diversos membros do corpo no espaço, temos uma "espacialidade de situação”. Isto é, eu sei onde está meu braço, meu antebraço, tronco, pés e pernas enquanto escrevo esse texto por um saber que é dado a partir da situação. Sei onde está meu corpo, “assim como um primitivo no deserto está a cada instante imediatamente orientado, sem precisar recordar e somar as distâncias percorridas e os ângulos de deslocamento desde o ponto de partida” (Merleau-Ponty, 2011, p.147). Assim, as posições das partes do corpo não são dadas pelas associações entre as partes, mas a partir de uma ancoragem do corpo ativo em um objeto, de um corpo situado, em face de suas tarefas.

Os objetos presentes na situação nos convidam a uma determinada tarefa. Merleau-Ponty discute o caso de Schneider, apresentado por Kurt Goldstein, um homem que, após um acidente perdeu a capacidade de fazer movimentos abstratos, quando recebe comandos como "pegue seu nariz”, mas que é plenamente capaz de pegar o nariz quando espirra ou um mosquito pousa nele. Quando ele é colocado diante dos objetos que eram parte de seu horizonte de trabalho - ele fabricava carteiras de couro - suas mãos executam com bastante precisão os movimentos, se apropriando da tesoura, da cola e do couro. $\mathrm{Na}$ situação, o corpo está ligado aos objetos como que por fios intencionais. A situação nos convida, nos apresenta uma tarefa aberta. Os objetos do mundo se apresentam como polos de ação: “eles definem por meio de seu valor combinado uma certa situação, e uma situação aberta, que exige um certo modo de resolução, um certo trabalho" (Merleau-Ponty, 2011, p. 154).

Com isso, o filósofo traz a existência "para fora", abandonando a interioridade da "alma" e a co- 
loca na situação, ao afirmar que o corpo é "apenas um elemento no sistema do sujeito e de seu mundo", "a tarefa obtém dele os movimentos necessários por um tipo de atração", assim como em determinado círculo social, a constelação de ouvintes obtém de nós determinadas falas e gestos que são convenientes. Segundo ele, isso ocorre não porque queremos agradar ou disfarçar nossos pensamentos, mas "porque literalmente somos aquilo que os outros pensam de nós e aquilo que nosso mundo é" (Merleau-Ponty, 2011, p. 154).

E como "sabemos" que esses movimentos são os necessários para executar determinada tarefa? Por que o meu corpo se estende no mundo como ação de determinada maneira e o corpo de meu amigo o faz de forma distinta? Por que pego minha caneta para escrever em certa articulação singular entre meu polegar e indicador que é diferente do mesmo colega que estudou comigo? Responder a essas perguntas é se direcionar ao corpo enquanto temporalidade. Como já dito, o corpo é ser no mundo, engajamento em determinada situação e isso significa que "meu olhar humano só põe uma face do objeto" que vejo (Merleau-Ponty, 2011, p. 105). Contudo, não nos limitamos a compreender o mundo a partir dessa face que se mostra visível para mim, mas fazemos uma síntese presuntiva: presumimos as faces que não estão disponíveis para minha perspectiva.

O tempo também é vivido como síntese, a experiência, como diriam os Gestalt-terapeutas se dá em um aqui-agora. Esse "aqui-agora" é síntese de dados do passado e possíveis futuros. Assim, quando saio do meu consultório no Centro do Rio, já é tarde e estou com fome. Como que por milagre, passo a perceber com quase insuportável clareza os sons e aromas do trailer de tapioca, da barraca de cachorro-quente e dos doces da Confeitaria Manon. Minha boca chega a salivar, mas lembro da dieta e das palavras da nutricionista, me ocorre que trouxe uma maçã na bolsa e estendo a mão para pegá-la, recuo antes de abrir a mochila, sei que o Centro do Rio à noite não é o lugar mais seguro e espero até entrar no metrô.

Essa síntese temporal e espacial marca o lugar do corpo como um "projeto motor" ou "intencionalidade motora", que se dirige às coisas do mundo para manipulá-las. A práxis, contudo, se apoia em sua dimensão que se tornou sedimento. O filósofo se refere a essa dimensão de formas distintas, mas que apontam para essa síntese de horizontes temporais: o "corpo habitual" e o "corpo atual", generalidade e pessoalidade, "fala falada" e "fala falante". Em todas existe um modo já apreendido, sedimentado, de se utilizar do corpo e que se torna suporte para a ação que a situação concreta exige.

Ele afirma que nosso corpo "comporta como que duas camadas distintas, a do corpo habitual e a do corpo atual" (Merleau-Ponty, 2011, p. 122). O corpo habitual é o fiador do corpo atual. Esse corpo habitual, segundo o filósofo, possui uma qualidade de generalidade, como ele aponta com o exemplo do amputado que ainda estende a mão que não possui mais para pegar o copo ou a garrafa quando sente sede. Isto quer dizer que o corpo não se orienta apenas a partir da situação singular e pessoal, mas possui uma dimensão impessoal, geral: o ato de pegar deixa de ser um para mim e se torna uma generalidade, pertence a todos e a ninguém em particular.

Segundo Merleau-Ponty, assim como fazemos do hábito motor extensão da existência, temos o hábito perceptivo como aquisição de mundo. Tendo em vista que nosso corpo é um campo perceptivo-prático, ele afirma que "todo hábito perceptivo é ainda hábito motor, e ainda aqui a apreensão de uma significação se faz pelo corpo" (Merleau-Ponty, 2011, p. 211). Traz como exemplo como uma criança se habitua a diferenciar o vermelho do azul. E é a partir dessa primeira diferenciação que ela passa a reconhecer todas as outras cores com mais facilidade. É através desse primeiro par de cores que vai apreender a significação de "cor". Ele diz que

Com o olhar, dispomos de um instrumento natural comparável à bengala do cego. O olhar obtém mais ou menos das coisas segundo a maneira pela qual ele as interroga, pela qual ele desliza ou se apoia nelas. Aprender a ver as cores é adquirir um certo estilo de visão, um novo uso do corpo próprio, é enriquecer e reorganizar o esquema corporal. (Merleau-Ponty, 2011, p. 212)

Porque nosso corpo não nos impõe, como o do animal, instintos definidos desde o nascimento, ele pode fazer esse movimento pendular entre o sedimentado em nossa existência e a novidade, entre habitual e o atual. Na produção de um ato abstrato, faço do meu próprio corpo finalidade e retomo a generalidade para brincar com minha existência e assim atuo, conto histórias, como o ator que chora como se o par tivesse morrido e que se anima como se existisse, de fato, determinada situação que exigisse seu ânimo. Como não estamos presos às determinações do instinto, podemos nos perguntar: "como somos corpo?" ou "que corpo temos?" . No início desse parágrafo temos um vislumbre de que há uma forte imbricação entre o corpo que experienciamos e as potências do corpo sedimentadas em nossa cultura. Esse processo aponta para a relação do corpo com mundo como corpo feito pelo mundo e produtor de mundo. É esse processo que pretendemos explorar a seguir.

\section{Merleau-Ponty e a dimensão cultural do corpo}

Como já apontamos, no centro do pensamento de Merleau-Ponty há uma crítica à compreensão e

$5 \quad$ Essa discussão também é apresentada, de passagem, nos seminários de Fritz, presentes no livro Gestalt-terapia Explicada (Perls, 1969, p. 97) 
ao método das ciências de sua época, fortemente influenciadas pelo intelectualismo, caracterizado por uma produção de sentido que é baseada em uma razão que apreende o mundo a partir de uma série de relações lógico-quantitativas. Já discutimos também que esse modo acaba por produzir as cisões de sujeito-objeto, corpo-mente e natureza-cultura.

Portanto, faz-se necessário uma compreensão do social e da cultura que busque superar essas cisões. Assim, o filósofo evoca Marcel Mauss e sua contribuição para a mudança de um paradigma que pretendia "tratar os fatos sociais como coisas" (Merleau-Ponty, 1980, p. 193), o que acabaria por reduzir a cultura ao psíquico. Isto é, a noção de que o social emergiria de representações que viriam de uma espécie de "consciência coletiva” que está alhures, externo ao indivíduo.

Esta compreensão sociológica, à semelhança do que dizíamos acima, "falava como se pudesse sobrevoar seu objeto e o sociólogo era um observador absoluto" (Merleau-Ponty, 1980, p. 194). Segundo o filósofo, faltava uma "penetração no objeto [o social] e a comunicação a ele” (Merleau-Ponty, 1980, p. 194) e Mauss teria feito essas práticas instintivamente. Ao penetrá-lo, encontra-se uma série de elementos: "a maneira sistemática como [determinada cultura] regula o emprego dos utensílios, dos produtos manufaturados ou alimentícios, das fórmulas mágicas, dos ornamentos, cantos, danças, elementos míticos . . . , vocabulário, sintaxe” (Merleau-Ponty, 1980, p. 194). Merleau-Ponty prossegue afirmando que o fato social é uma rede de valores simbólicos e que "vai inserir-se no individual mais profundo” (Merleau-Ponty, 1980, p. 195). Com isso, não haveria mais necessidade de manter-se dividido entre individual e coletivo, nem encontrar leis absolutas para as sociedades. Inclusive ele aponta que, para Mauss, o foco deixa de ser os fenômenos compreendidos como abstração e se torna o humano de cada cultura: ““O verdadeiro', escreve Mauss, 'não é a prece nem o direito, mas o melanésio de tal ou tal ilha, Roma, Atenas"” (Merleau-Ponty, 1980, p. 194).

A ideologia moderna parte do pressuposto de um homem "autônomo, independente de todo e qualquer vínculo social ou político” (Dumont,1993, p. 87) e a entrada do indivíduo na sociedade seria sempre feita a partir de um ato voluntário, possível pela razão. O indivíduo, assim, precederia o social e, quiçá, a própria cultura, pois só participaria dela por meio de uma escolha. Para Merleau-Ponty, o sociocultural vivido pelo indivíduo não se apoia em uma consciência reflexiva, mas antes em uma experiência intuída do viver naquela cultura, uma apreensão corporal. Nossa afiliação ao mundo cultural acontece antes de qualquer escolha deliberada ou racional (Alvim, 2018), por meio de um corpo cognoscente. As estruturas - de troca, religião, comércio, mito que compõem uma determinada sociedade não são percebidas pelos sujeitos como um objeto alhures com que interagem, mas são vividas e praticadas como se fossem óbvias.

Merleau-Ponty (1975) define estrutura como "configuração ou forma que expressa um sentido" (Alvim, 2014, p. 36), integração perceptiva das dimensões biológicas, psicológicas e sociais em um campo fenomenal. Ele descreve essa integração em três ordens: 1) física ou material, 2) vital e 3) humana ou simbólica. A ordem física seria a própria matéria, concretude tangível, regida por leis físicas, imutáveis e concretas. A ordem vital refere-se ao fisiológico, à vida e aos atos de criação dos organismos no mundo na tentativa de satisfazer suas necessidades. Segundo Alvim,

Na ordem física, a significação está na lei, que conserva uma ordem dada. Na ordem vital, a significação se define a partir da situação que engloba organismo e ambiente e obedece a uma norma que é singular, o caminho mais adequado para aquele organismo que tem atividade e efetivamente age. (Alvim, 2014, p. 41)

A ordem humana ou simbólica se refere a produção de sentido em curso na percepção do mundo pelo humano. Segundo Merleau-Ponty, perceber é um trabalho do corpo, que no ato de percepção transforma a Natureza e interpõe a ela usos e objetos culturais, a capacidade de lançar-se da situação concreta e passar à virtualidade. $\mathrm{O}$ ser humano é organismo que se ajusta de forma criativa às possibilidades que o mundo físico e vital e humano lhe oferece, afirmando uma relação inextricável com o mundo, que existe antes de mim, e no ato de existir me solicita.

Merleau-Ponty afirma que:

Assim como a natureza penetra até no centro da minha vida pessoal e entrelaça-se a ela, os comportamentos também descem na natureza e depositam-se nela sob a forma de um mundo cultural. Não tenho apenas um mundo físico, não vivo somente no ambiente da terra, do ar e da água, tenho em torno de mim estradas, plantações, povoados, ruas, igrejas, utensílios, uma sineta, uma colher, um cachimbo. Cada um emite uma atmosfera de humanidade que pode ser muito pouco determinada, se se trata de algumas marcas de passos na área, ou ao contrário muito determinada, se visito todos os cômodos de uma casa recém-desocupada. (Merleau-Ponty, 2011, p. 465)

Quando nascemos, nos deparamos com esse mundo que não é só ordem física e vital, mas humana: um mundo sedimentado pelos comportamentos de outrem e que ficam ali pousados como uma coisa anônima, uma generalidade.

A apreensão do mundo pelo corpo também se dá quando, ao nascermos, tateamos os corpos dos 
outros com nosso corpo. Compreendemos as intenções desses outros corpos, identificando neles potências que percebemos em nós e assim, apreendemos a significação destes atos.

Um bebê de quinze meses abre a boca se por brincadeira ponho um de seus dedos entre meus dentes e faço menção de mordê-lo. . . . Isso ocorre porque sua própria boca e seus dentes, tais como ele os sente do interior, são para ele imediatamente aparelhos para morder, e porque minha mandíbula, tal como ele a vê do exterior, é para ele imediatamente capaz das mesmas intenções. A "mordida" tem para ele imediatamente uma significação intersubjetiva. Ele percebe suas intenções em seu corpo, com o seu corpo percebe o meu, e através disso percebe em seu corpo as minhas intenções. (Merleau-Ponty, 2011, p. 472-473)

Da mesma forma como quando vejo alguém agir no mundo, quando um pai ou mãe toca um instrumento ou aperta o interruptor de luz, a partir desse ato, os objetos ao redor ganham uma nova camada de significação iluminada por essa ação:

(...) eles [os objetos do mundo] não são mais apenas aquilo que eu mesmo poderia fazer com eles, são aquilo que este comportamento vai fazer com eles. Em torno do corpo percebido cava-se um turbilhão para onde meu corpo é atraído . . . . O outro [se torna] . . . o lugar de uma certa elaboração e como que de uma certa visão do mundo. (Merleau-Ponty, 2011, p. 474)

Em “A Percepção do Outro e o Diálogo", texto de Merleau-Ponty, escrito entre 1950 e 1952 e publicado após a sua morte, o filósofo propõe-se a pensar como o outro é percebido, já que a proposta idealista é um paradoxo: se minha subjetividade constitui mundo, o outro é objeto no meu mundo, o que anularia a consciência dele. Viveríamos em disputa, meu mundo contra mundo dele. Para que haja a percepção do outro é necessário um terreno comum, um espaço de partilha.

O mundo não existe apenas para mim, mas é maior que minha própria existência e compreende também a existência dos outros. Como o próprio filósofo exemplifica, o sol que queima minha pele é o sol que arde na testa do homem que dorme no banco da praça, e eu e o homem sentimos em nosso corpo a mesma "mordida do mundo" (Merleau-Ponty, 2007, p. 224). Simultaneamente, esse mesmo mundo que partilho é percebido a partir do fundo da minha existência, da história do meu corpo. Em minha experiência, sinto que o sol de meio dia me faz mal, como já o fez outra vez, ou como já ouvi ou vi fazer. Isso surge para mim antes como incômodo ou desconforto que sinto, do que na reflexão.
A percepção do outro se dá nessa contiguidade de quem partilha um mundo, mas também na diferença que me desloca e me desafia. Se, por exemplo, eu adormeço debaixo do sol e desperto do meu sono, incomodado com o calor, logo me apresso em cobrir-me e proteger minha pele. Contudo, logo ali, avisto uma moça que se regala com o brilho e o calor que tosta a sua pele. Percebo-a como diferença que me desloca, pois vivo em mim mesmo as intenções daquele "eu que está alhures" (Merleau-Ponty, 2007, p. 224). E esse ato que me desloca, ao comunicar-se a mim, se torna sedimento em minha existência, passa a surgir como possibilidade do meu agir no mundo.

O mundo cultural é um mundo de partilha. Quando crianças, somos solicitados a partilhar desse mundo que surge a partir dos outros e que é generalidade: fala-se, anda-se, corre-se, ou mexe-se. As situações nos convocam e nos engajam e essas experiências inicialmente são vividas como o milagre da descoberta pessoal. E por estarmos afiliados a esse mundo, não vemos as coisas como uma "tábula rasa”, mas brotamos de um sedimento que tinge de mil tons de intenções os objetos ao redor, e as apreendemos com o corpo, fazemos deles coisas nossas e, posteriormente, sedimentos de nossa existência, que repousam em um horizonte de perspectivas.

A partir daí podemos afirmar que o mundo cultural e o social existem antes de qualquer pessoalidade e que "nossa relação ao social é mais profunda que qualquer percepção explícita ou qualquer juízo" (Merleau-Ponty, 2011, p. 485). Nossa história é permeabilidade com o mundo e com o outro. É um encontro de perspectivas, onde umas escorregam nas outras, sedimentando um mundo conjunto, como na experiência do diálogo, onde “. . . nós somos, um para o outro, colaboradores em uma reciprocidade perfeita, nossas perspectivas escorregam uma na outra, nós coexistimos através de um mesmo mundo" (Merleau-Ponty, 2011, p. 475). Tornar-se alguém é também encarnar os outros, apreender a significação de seus hábitos com meu corpo, brotar da generalidade.

Vejamos o poema de Leminski, "Contranarciso":

em mim
eu vejo o outro
e outro e outro
enfim dezenas
trens passando
vagões cheios de gente
centenas
o outro
que há em mim
é você
você
e você
assim como
eu estou em você
eu estou nele
em nós ... (Leminski, 2013, p. 32)


Em meu corpo estão os gestos da minha mãe ao preparar o alimento na cozinha, o modo de falar de meus professores pode ser percebido quando eu ministro meu curso e em determinados momentos eu vejo em meu ato: o eco do estilo do amigo de longa data, certa forma de rir ou ficar bravo que via na minha companheira e agora vejo revivida em mim de uma maneira singular.

É a partir desse lugar que sou alguém, sendo esse o sentido da noção de estilo em Merleau-Ponty. Desse modo, o processo civilizatório também nos insere em um lugar de pertença a um gênero e apreendo determinada forma de andar, sentar, falar e se expressar, assim como formas de sentir e perceber meu corpo e o corpo do outro. Em mim, em (m)eu-corpo mora o mundo, que insiste em brotar diante das situações com que engajo no mundo, sou uma obra de arte sempre em processo de fazer-se com as cores, tons, e pinceladas que vejo o outro executar e com as quais brinco, re-criação (recreação) desse elemento de mundo que habita todos.

Por fim, é importante marcar que, de modo algum, essa permeabilidade com o mundo nos faz dissolvido nele. A proposta é compreender a existência em sua ambiguidade, essa tensão entre o singular e o universal:

Nesta situação ambígua na qual somos lançados porque temos um corpo e uma história pessoal e coletiva, não conseguimos encontrar repouso absoluto, precisamos lutar o tempo todo para reduzir nossas divergências, para explicar nossas palavras mal compreendidas, para manifestar nossos aspectos ocultos, para perceber o outro. (Merleau-Ponty, 1948/2004, p. 50).

\section{A clínica gestáltica: corpo e diálogo no campo organismo/ambiente}

A compreensão merleau-pontyana de um corpo vivo, que conhece e dá sentido ao mundo no processo de viver, convida-nos também a ampliar nosso próprio olhar para duas noções importantes na teoria da Gestalt-terapia: contato e a noção de campo organismo/ambiente.

O contato, na perspectiva gestáltica, é "a realidade mais simples e primeira” (Perl et al., 1997, p. 23), e isso é uma proposição que, a princípio pode parecer simples, mas que na realidade tem várias consequências. Uma delas é que, ao afirmar isso, os autores deslocam o objeto da psicologia do centro do sujeito para as interações na fronteira de contato no campo organismo/ambiente. O que eles estão afirmando é que nosso olhar deve se voltar para as interações, isto é, que o indivíduo e seu comportamento ou cognição estão sempre em relação com outros elementos do campo. Ao fazermos essa mudança de foco, percebemos que a realidade e a experiência não são frutos apenas de uma introjeção, projeção, fantasia ou ilusão, mas que é uma gestalt que emerge do encontro, do toque, do fluxo de afetações ou trocas entre o que é eu e o que é mundo.

O trabalho com a epistemologia de campo aplicado na prática clínica também considera que o que surge como discurso na sessão não é algo que fala apenas do cliente, mas brota da situação aqui-agora, onde eu enquanto terapeuta, meu olhar, minha postura, minhas perguntas, em suma, minha presença é elemento essencial dessa fala/diálogo co-criado. Nesse sentido, Robine (2015) descreve o self como espontâneo e Alvim (2014) compreende o ato espontâneo como aquele que brota da situação: não é uma brincadeira autocentrada, mas é uma criação que está o tempo toda apoiada na situação aqui-agora.

Dessa forma, o trabalho na terapia não é mudar o que se sabe sobre si e construir explicações, mas experimentar como acontece o contato, como há ou não integridade na figura de contato, e assim, oferecer suporte à construção de gestalten (ROBINE, 2006), convite a ficar aware de como acontece esse contato, como ele é suprimido ou interrompido e isso só é possível através de um convite para o abandono das seguranças do hábito que não responde à situação atual e explorar a partir da função id o contato como realidade primeira, a experiência de estar encarnado no mundo, comigo e com o outro.

Ao afirmarem também que "todo contato é ajustamento criativo do organismo e do ambiente" (Perls et al., 1997, p. 45) Perls, Hefferline e Goodman também descartam a Gestalt-terapia como uma psicoterapia individualista. Pelo contrário, mais adiante no livro eles afirmam que o trabalho psicoterápico sem transformação do ambiente só produz um alívio momentâneo. A psicoterapia gestáltica construída sobre a noção de contato implica então um olhar que se volta para o inter e não para o intra. Antes de ser uma "viagem para dentro de si" é mais um processo de "estar com" e da co-criação de um diálogo que produza deslocamentos.

O processo de contato pode ser compreendido como um fluxo temporal de uma Gestalt que emerge de um fundo e retorna a ele, o enriquecendo. $\mathrm{O}$ processo de pré-contato é articulação de um passado que está sedimentado no mundo e no corpo (como hábitos, cultura, linguagem, moral, costumes, etc.), diante de uma situação de novidade que se faz presente. Esse processo de dissolução do que está dado e manipulação da novidade é sempre um "descobrir-e-inventar" (Perls et al., 1997) a solução vindoura, marcando o lugar da situação no processo de contato e ajustamento criador e afirmando uma perspectiva não-individualista.

No fluxo temporal do contato, o self emerge operando prioritariamente na função id, que marca nossa situação de seres engajados no mundo, contíguos com ele e passa a operar na função ego, que é ação motora, ato de criação e transformação dos elementos do campo organismo/ambiente, dança transformadora com o mundo que, a partir do que é "dado" 
no campo, criação de novas formas, outras possibilidades de gesticular e me movimentar no mundo. Ao fim do contato, no pós-contato, quando a novidade é assimilada e retornamos para o fundo, o self opera na função personalidade, que funciona na elaboração de representações e, ao fazê-lo, elas também caem no mundo, e produzem cultura, um mundo de partilha (Alvim, 2014; 2018; Merleau-Ponty, 2011).

Não por acaso, a Gestalt terapia busca ampliação da awareness e utiliza essa palavra em vez de "consciousness". A awareness é também a afirmação do saber do corpo que dá sentido para o mundo antes de qualquer reflexão. A tradição gestáltica é se dirigir ao cliente perguntando o que ele sente aqui-agora. Isto é, um convite para a possibilidade de ouvir e dar voz a esse corpo que no seu "sentir" faz uma operação de síntese dos elementos do campo organismo/ambiente.

Diante de um corpo que nos aparece anestesiado na situação clínica, enfatizamos a concepção do trabalho em terapia conforme Perls, Hefferline e Goodman propõem, e aqui colocado a partir da compreensão de Alvim: "recobrar o fluxo temporal impedido para permitir a reabertura dos horizontes e o contato com a realidade presente" (Alvim, 2018). Isso possibilitaria ampliação da awareness através da ênfase na função id do self, enfatizando o caráter sensível e a dimensão pré-reflexiva da experiência, como momento de abertura e afetação para a situação presente, elementos essenciais para o contato com a diferença e reestabelecimento da experiência de vinculação com o mundo.

O encontro se dá na nessa dimensão corporal, pré-reflexiva, que é o momento de indiferenciação com o campo, quando sistema self de contatos opera na função id. A experiência suportada pela função id abre a possibilidade de sentir com o outro - id da situação - e assim posso experimentar a alteridade como comunhão de mundo, mas também como diferença que me desloca. Nisto está certo efeito perverso do individualismo: ao constituir-nos separados também nos afastamos de nosso corpo - que é o vinculador a todas as coisas - e da experiência sensível, indispensável para o encontro.

A proposta de presença do terapeuta enquanto abertura sensível, "terapeuta marginal” (Alvim, 2012), que não se apega uma suposta neutralidade, mas que se implica na situação levaria ao que Robine chamará de um "desvelamento de si", um "modo de aparecer aos olhos do outro de seu cliente que leva este último a constituí-lo também enquanto outro, e assim, preocupar-se com a alteridade." (Robine, 2015, p. 131). Segundo ele, aparecer para o cliente como um outro seria capaz de recompor a "distância intersubjetiva". Tal como discutem Alvim e Castro (2015), uma ética da alteridade, onde um é sujeito para o outro, não prescinde, ontologicamente, do compartilhamento de um terreno comum de humanidade.

Nessa direção, Robine marca a importância de que trabalhar a partir da perspectiva de campo dá abertura a um trabalho feito a partir dos "movimentos que permitem a passagem do indiferenciado ao diferenciado", da fusão a separação, o que nos leva a trabalhar também as noções de autonomia e dependência, influência e manipulação. E conclui dizendo que a "experiência dos fenômenos inerentes à relação terapêutica - que não se reduzem somente aos fenômenos transferenciais - constitui um terreno de experimentação do vínculo e do pertencimento que são muito deficitários em nosso contexto social. " (Robine, 2015, p. 132)

\section{Conclusão}

Consideramos que a Gestalt-Terapia apresenta em sua obra original de 1951 uma proposta de terapia que, buscando combater "dicotomias neuróticas" (Perls et al., 1997, p. 54) que predominam universalmente e se dissolvem na história da psicologia, adotam uma perspectiva de campo que pressupõe uma compreensão não individualista do ser humano. As leituras produzidas a partir dessa obra, que como discutimos, traz algumas contradições onde convivem nuances de perspectivas modernas e que tendem ao individualismo e pós-modernas que tendem ao campo, tiveram como reflexo desenvolvimentos distintos de conceitos centrais na teoria gestáltica, como campo organismo/ambiente, self, fronteira de contato, contato e ajustamento criador. A compreensão de campo que aqui discutimos não está, assim, incorporada de modo homogêneo na abordagem, o que pode levar a alguns mal-entendidos.

Como foi apontado pelos fundadores da Gestalt-terapia e profundamente discutido pelo filósofo Merleau-Ponty, tomar o corpo como origem é um caminho de superação das dicotomias que se fundam no pensamento moderno, idéia também corroborada por Le Breton (2011) e Dumont (1994). Compreender a potência do corpo para além de matéria e fisicalidade e entender que ele faz parte de um dimensão partilhada, coletiva, de alguma maneira "explode" os limites impostos por esse corpo individual e fechado e coloca o corpo-sujeito como produzido e produtor do mundo, dele inseparável. Fica aqui a radical contribuição da abordagem gestáltica, ainda hoje atual e necessária. Em tempos onde as demandas do mundo social apontam para um corpo cada vez mais anatomizado e solicitado a operar como máquina, consideramos que a perspectiva radical de campo deve ser a tônica do nosso fazer clínico.

\section{Referências}

Alvim, M. B. (2014). A poética da Experiência: Gestalt-terapia, fenomenologia e arte. Rio de Janeiro: Garamond.

Alvim, M. B., \& Castro, F. G. (2015). Clínica de situações contemporâneas: fenomenologia e interdisciplinaridade. Curitiba: Juruá. 
Alvim, M. B. (2018). Id da situação como solo comum da experiência. In: J.M. Robine (org.). Self: uma polifonia de Gestalt-terapeutas contemporâneos. São Paulo: Escuta.

Le Breton, D. (2011). Antropologia do corpo e modernidade. Petrópolis, RJ: Vozes.

Dumont, L. (1993). O individualismo: uma perspectiva antropológica moderna. Rocco.

Heidegger, M. (2007). A questão da técnica. Scientiæ studia, 5(3), 375-398.

Leminski, P. (2013). Toda poesia. Editora Companhia das Letras.

Maia, G. \& Sevilla, M. (2015, 19 de novembro). Índios lamentam tragédia em MG: 'O rio Doce sabia que ia ser morto'. UOL Notícias. Recuperado de: http://noticias.uol.com.br/cotidiano/ ultimas-noticias/2015/11/19/indios-lamentam-tragedia-em-mg-o-rio-doce-sabia-que-ia-ser-morto.htm

Mancebo, D., \& Jacó-Vilela, A. M. (2004). Psicologia social: abordagens sócio-históricas e desafios contemporâneos. Rio de Janeiro: EdUERJ.

Merleau-Ponty, M. (1980). De Mauss a Claude Levi-Strauss. In: . Os Pensadores: Textos selecionados. São Paulo: Abril Cultural.

Merleau-Ponty, M. (2002). A percepção do outro e o diálogo. In: Cosac \& Naify.

Merleau-Ponty, M. (2004). Conversas-1948. São Paulo: Martins Fontes.

Merleau-Ponty, M. (2006). A estrutura do comportamento. São Paulo: Martins Fontes.

Merleau-Ponty, M. (2011). Fenomenologia da percepção. São Paulo: WSF Martins Fontes.

Napier, A. D. (2012). Nonself help: how immunology might reframe the Enlightenment. Cultural Anthropology, 27(1), 122-137.

Pereira, O. P. (2003). A reconstruçäo do corpo e do tempo no diálogo transcultural. Rev. bras. crescimento desenvolv. hum, 13(2), 95-104.

Perls, F. (1969). Gestalt-terapia explicada. Summus Editorial.

Perls, F; Hefferline, R.; Goodman, P. (1997). Gestalt-terapia, São Paulo : Summus.

Perls, L. (1992). Living at the Boundary: Collected Works of Laura Perls. Gestalt Journal Press Bookstore.
Phillippson, G. (2018) Self e o Outro. In: J.M. Robine (org.). Self: uma polifonia de Gestalt-terapeutas contemporâneos. São Paulo: Escuta.

Robine, J. M. (2005). A Gestalt-terapia terá a ousadia de desenvolver seu paradigma pós-moderno?. Estudos e Pesquisas em Psicologia, 5(1).

Robine, J. M.. (2006). O self desdobrado: perspectiva de campo em gestalt-terapia. São Paulo: Summus.

Robine, J. M.. (2015) A mudança social começa a dois e Implicações Sociais da Gestalt-terapia. In: M.B. Alvim; F.G. de Castro (org.) Clínica de Situações Contemporâneas: Fenomenologia e Interdisciplinaridade. Curitiba: Juruá Editora.

Silva, A. M. (1999). Elementos para compreender a modernidade do corpo numa sociedade racional. Cadernos Cedes, 48(19), 7-29.

Rafael de Oliveira Lins (orcid.org/0000-00015541-1657), Professor Substituto do Departamento de Psicologia Clínica, Instituto de Psicologia, Universidade Federal do Rio de Janeiro (UFRJ). Mestre em Psicologia pelo Programa de Pós-graduação em Psicologia (PPGP/UFRJ). Colaborador do Núcleo de Estudos Interdisciplinares em Fenomenologia e Clínica de Situações Contemporâneas - NEIFeCS. E-mail: rafaellins.psi@gmail.com

Mônica Botelho Alvim (orcid.org/0000-0003-35224154), Professora Associada do Departamento de Psicologia Clínica e Coordenadora do Programa de Pós-Graduação em Psicologia, Instituto de Psicologia, Universidade Federal do Rio de Janeiro (UFRJ). Membro do GT Fenomenologia e Psicologia - ANPEPP. Co-Coordenadora do Núcleo de Estudos Interdisciplinares em Fenomenologia e Clínica de Situações Contemporâneas - NEIFeCS e Diretora Técnico-Científica da Associação Brasileira de Gestalt-Terapia-ABG. Endereço Institucional: Av. Pasteur, 250, Urca, Rio de Janeiro - RJ. CEP: 22290250. Universidade Federal do Rio de Janeiro - Pavilhão Nilton Campos. E-mail: monica.alvim@ufrj.br

Recebido em 14.08.2018 Primeira Decisão Editorial em 23.04.2019 Aceito em 08.09.2019 